\title{
Composite anion exchange membrane made by layer-by-layer method for selective ion separation and water migration control
}

\author{
Yufei Zhang, ${ }^{\mathrm{a}, \mathrm{b}, \mathrm{d}}$, Ru Liu ${ }^{\mathrm{a}, \mathrm{b}, \mathrm{d}}$, Qiaolin Lang ${ }^{\mathrm{a}, \mathrm{c}}$, Ming Tan ${ }^{\mathrm{a}, \mathrm{c}, *}$, Yang Zhang ${ }^{\mathrm{a}, \mathrm{c}, *}$ \\ a Waste Valorization and Water Reuse Group (WVWR), Qingdao Institute of Bioenergy and Bioprocess Technology, Chinese Academy of Sciences, 189 Songling Road, \\ Laoshan District, Qingdao 266101, China \\ b State Key Laboratory of Petroleum Pollution Control, Beijing 102206, China \\ c Qingdao Key Laboratory of Functional Membrane Material and Membrane Technology, Qingdao Institute of Bioenergy and Bioprocess Technology, Chinese Academy of \\ Sciences, Qingdao 266101, China \\ d University of Chinese Academy of Sciences, 19A Yuquan Road, Beijing 100049, China
}

\section{A R T I C L E I N F O}

\section{Keywords:}

Electrodialysis

Layer-by-layer method

Organic ion separation

Water permeance

Selectivity

\begin{abstract}
A B S T R A C T
In ion exchange membrane processes (e.g. electrodialysis), improving ion selectivity and reducing water permeance are two key concerns, which drive new membrane fabrication methods. Preparation of composite ion exchange membrane with functional layers may be a solution to elevate its performance. In this study, composite anion exchange membranes (C-AEM) were prepared by using layer-by-layer (LbL) method, and were characterized with regard to membrane surface properties, selectivity, as well as water permeance. Results indicate that monovalent ion selectivity increased with the number of assembled layers. More specifically, when the membrane was modified with 10.5 layers, $\mathrm{P}_{\mathrm{SO}_{4}^{-}}^{-}$reached over 10, which was much higher than the commercially available monovalent selective membrane (ACS, $\mathrm{P}_{\mathrm{SO}_{4}^{2-}}^{-}$around 5). Besides, the C-AEMs also showed a good performance on organic ion selectivity and water migration control. This work proves that LbL method is an effective way to prepare functionalized ion exchange membrane by controlling membrane surface properties (surface potential and pore size). Furthermore, this work provides an investigation of transport mechanisms of ions with different charge, different size and different hydration number by penetrating functional membranes with layered top structure. The prepared C-AEMs showed a good separation efficiency of monovalent ions and organic acids with controlled water migration, this may be potentially used in desalination, wastewater treatment, chemical separation, or other related fields.
\end{abstract}

\section{Introduction}

As the improvement of membrane material and fabrication techniques, a series of membrane processes driven by pressure difference, concentration difference and potential difference, play a vital role in the separation, enrichment, purification and other applications [1]. As an electro-driven membrane process, electrodialysis (ED) employs ion exchange membranes for ion separation, which has been proven as an emerging technology to separate salt and charged molecules from water [2-4]. The related electrodialysis applications can be found in various fields such as waste acid recovery [5], brine reclamation [6], and fermentation engineering [7].

However, functional ion exchange membranes are required in some specific applications, e.g. membranes with monovalent selective properties used for production of table salts from seawater [8,9], or membranes with different cavity sizes applied to purify organic acids with various molecular weight $[10,11]$. The general principle of mono/divalent ions separation attributes to two mechanisms, i.e., steric-hindrance and electrostatics repulsion [12]. More specifically, the separation factor depends on the hydrated size of the ions, the hydrophilicity of the membrane and the charge on the membrane surface [2].

To date, different approaches to fabricate monovalent selective anion exchange membrane (AEM) have been reported. For example, formation of a highly cross-linked layer on the membrane surface has been reported to be an effective method [13]. However, the rigid structure would inevitably increase the electrical resistance. The formation of condensation-type polyelectrolyte [14] and weakly basic anion exchange group layer [15], as well as the hydrophilicity according to the anionic species $[2,16,17]$, all hinder the improvement of ion selectivity. Commercially available monovalent anion selective membranes such as ACS (Astom, Japan) have been widely used in

\footnotetext{
* Corresponding authors.

E-mail addresses: tanming@qibebt.ac.cn (M. Tan), zhangyang@qibebt.ac.cn (Y. Zhang).
} 
practical applications [18]. However, the separation factor $P_{\mathrm{Cl}^{4}}^{\mathrm{SO}^{2-}}$ is about 0.4 , which still needs further development to fractionate salts with higher purity [19].

A promising approach has been proposed in which the membrane surface is modified with a thin and charged layer. It is reported that monovalent anion selective membranes with anionic polyelectrolytes, such as poly (sodium 4-styrene sulfonate) [19], polydopamine [20] and poly-vinyl-sulfate [21] have been fabricated, but the permselectivity of these membranes $\left(\mathrm{Pll}_{\mathrm{Cl}^{-}}^{2-}\right)$ were ranging from 0.4 to 0.22 , which was still not enough to achieve an efficient separation of sulfate from chloride. A method with layer-by-layer (LbL) assembly of polyelectrolyte multilayers was found to be a good alternative [21]. In this method, alternating adsorption of polycations and polyanions on AMX (Astom, Japan) membrane leads to a high monovalent/divalent anions permselectivity with an odd number of LbL layers (poly sodium-p-styrenesulfonate top layer) above 15 [19]. It was reported that the amount of negative charge increases with increasing numbers of layers [22,23].

On the other hand, separation of organic ions is highly needed in fermentation and chemical synthesis industries [24]. The mechanisms of organic acids separation by functional membrane are mainly explained size exclusion, electrostatic repulsion and hydrophobic/hydrophilic adsorption.

Molecular size and charge number effects were mostly investigated in organic ion transport through ion exchange membranes in electrodialysis [24]. Moon and the co-workers [24] reported separation of mixed organic ions by electrodialysis with standard and monovalent selective membranes. Results showed that binary organic ion (succinate) can be separated from formate or acetate through monovalent selective anion exchange membrane due to size exclusion and electrostatic repulsion. However, it is difficult to separate organic ions with the same charge number [24].

Zhang et al. [25] reported that aspartate was removed faster than butyrate, which attributed to the hydrophobic/hydrophilic adsorption. Takahashi et al. [26] also explained the transport mechanisms of single, binary, and ternary acids in view of the hydrophobic/hydrophilic interaction between organic ions and the membrane surface. Huang et al. reviewed various electrically driven membrane processes in production of organic acids by electrodialysis, and pointed out that although ED has shown competence in this field, development of specific selective ion exchange membranes for separating organic ions is an important goal [25].

Water co-transport with salts in electrodialysis is another important issue need to be solved. As the ions exist as hydrated forms in aqueous solution, ion migration in electrodialysis always result in water volume increase in the concentrate, this hinders further concentration of salt. Han et al. [27] calculated hydration number of four ions $\left(\mathrm{Na}^{+}, \mathrm{Mg}^{2+}\right.$, $\mathrm{Cl}^{-}, \mathrm{SO}_{4}{ }^{2-}$ ) by using volume difference in the concentrate after electrodialysis process. Results showed that the hydration number of sodium, magnesium, chloride and sulfate ions was $6,15-16,8,13-14$, respectively. A similar work had been done by Jiang et al. [28], they investigated water electro-transport with hydrated cations in ED. The work indicated that water electro-transport is significant and cannot be ignored. The authors also suggested that ion exchange membrane should be designed to mitigate water electro-transport by reducing hydrophilicity or increasing membrane cross-linkage (i.e., to make a "more dense" membrane).

As discussed above, ion hydration numbers not only influence ED performance, but also significantly affect ion selectivity, since a higher hydration number result in a larger hydrated ionic size. As addressed, the hydration number of bivalent ions is much higher than that of monovalent ions, this induces a selectivity between monovalent and bivalent ions by ion exchange membranes in view of steric hindrance effect [27]. With regard to the commercially available ion exchange membranes, development of membranes with effectively retain water co-transport function is still in a gap for research and development.

Although LbL deposition method has been extensively used for NF and RO membrane modification to increase their performance [28-30], it has not yet well established for functionalization of ion exchange membranes. Furthermore, since LbL method controls membrane surface charge and top-layer "tightness", it gives a possibility to separate ions and reduce water migration by adjusting layers and cross-linkage.

Therefore, composite anion exchange membranes (C-AEM) prepared by LbL method are investigated in this work. Monovalent anion selectivity, organic ion separation efficiency and control of water cotransport are further investigated with regard to the coated layers, and compared with the base membrane and the commercial monovalent anion selective membrane. Functionalization of ion exchange membrane by layer-by-layer method is further discussed to explore a capable way to improve electro-driven membrane separation and purification efficiency.

\section{Experimental}

\subsection{Materials and chemicals}

A homogeneous TWEDA1 standard anion exchange membrane was used as the base membrane (Tianwei Membrane Technology Co., Ltd., Weifang, China). Membrane properties of TWEDA1 membrane and PCSK membrane (PCA GmbH, Heusweiler, Germany) were shown in Table 1 (data were provided by the manufacturer). In the electrodialysis experiments, PC-SK membrane was used as a cation exchange membrane (CEM). The polyelectrolytes coating solution, poly (sodium-pstyrenesulfonate) (PSS, $\mathrm{M}_{\mathrm{w}}=80,000,20 \mathrm{wt} \%$ aqueous solution) and poly (diallyldimethylammonium chloride) solution (PDDA, $\mathrm{M}_{\mathrm{w}}<1,00,000,35 \mathrm{wt} \%$ aqueous solution), were provide by Shanghai Macklin Biochemical Co., Ltd. Industrial grade graphene aqueous slurry (TNIGNP content $5.0 \mathrm{wt} \%$; dispersant $1.5 \mathrm{wt} \% ; \mathrm{H}_{2} \mathrm{O}$ content $93.5 \mathrm{wt} \%$; layers < 30) was bought from Chengdu Organic Chemicals Co., Ltd.

To investigate monovalent anion selectivity of the membranes, sodium chloride $(\mathrm{NaCl})$ and sodium sulfate $\left(\mathrm{Na}_{2} \mathrm{SO}_{4}\right)$ were used as the monovalent and divalent salts. In organic separation experiments, formic acid (AR, 88\%) and hexanoic acid (> 99.5\%, Aladdin biological technology Co. Ltd., Shanghai, China) were used. Besides, the sodium sulfate, sodium chloride, sodium hydroxide $(\mathrm{NaOH})$ and hydrochloric acid $(\mathrm{HCl}$ ) (purity $\geq 98 \%$ ) were all analytical grade regents (purchased from the Sinopharm Chemical Reagent Co., Ltd., China) without purification.

\subsection{Membrane preparation}

The PSS and PDDA solutions used for surface modification were prepared by dissolving $1 \mathrm{~g} / \mathrm{L}$ of PSS or PDDA with $1 \mathrm{M} \mathrm{NaCl}$ (as a supporting electrolyte) in deionized water. To reduce the electrical resistance caused by the coated layers, graphene was dissolved in PDDA solution with different proportion from 0 to $10 \mathrm{wt} \%$. Before the AEM

Table 1

The properties of ion exchange membrane used in the experiments.

\begin{tabular}{|c|c|c|c|c|c|c|}
\hline Membrane & Thickness $(\mu \mathrm{m})$ & Ion exchange capacity (mequiv./g) & Chemical stability $(\mathrm{pH})$ & Water content (wt $\%$ ) & Functional groups & Area resistance $\left(\Omega \cdot \mathrm{cm}^{2}\right)$ \\
\hline TWEDA1 & $10-50$ & $0.9-1.1$ & $1-12$ & $15-20$ & $-\mathrm{NR}_{4} \mathrm{Cl}$ & $\leq 2.50$ \\
\hline PC-SK & $160-200$ & c.a. 1 & $0-11$ & $\sim 9$ & $-\mathrm{SO}_{3} \mathrm{Na}$ & 2.50 \\
\hline
\end{tabular}


(a)

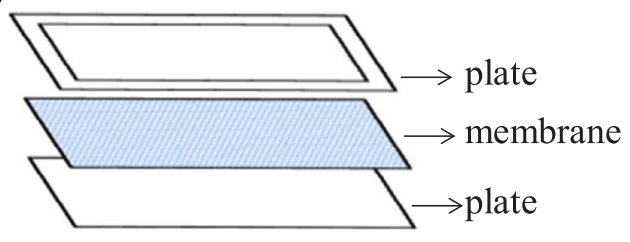

(b)

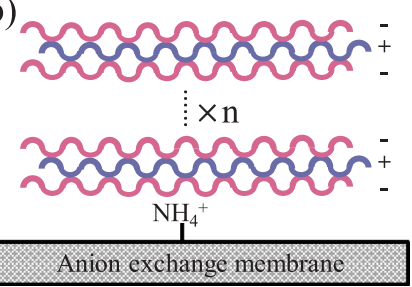

Fig. 1. Schematic diagram of (a) the LbL assembly template; (b) the LbL method for functionalization of the anion exchange membrane. membrane was clamped between two plates (Fig. 1a), it was soaked in the deionized water for $2 \mathrm{~h}$.

Firstly, $0.1 \mathrm{M} \mathrm{NaOH}$ was used to activate the membrane surface for about $15 \mathrm{~min}$, then alternately the membrane was soaked with $0.1 \mathrm{M}$ $\mathrm{HCl}$. The LbL assembly was applied only on one side of the base anion exchange membranes, and the procedure is described as following: (1) $70 \mathrm{ml}$ PSS solution was coated on the membrane surface for $30 \mathrm{~min}$, following by rinsing away the residual liquids with deionized water. (2) $70 \mathrm{ml}$ PDDA solution was coated for another $30 \mathrm{~min}$; (3) PSS and PDDA coating was repeated; (4) the procedure was ended up with an odd number of layers, which means that the top layer was PSS, as shown in Fig. 1b. The membrane with assembled layers is named as C-AEM-n (n represents the number of layers, 5 layers means 5 layers of PSS and 5 layer of PDDA, 5.5 layer means 6 layers of PSS and 5 layers of PDDA). The membrane with graphene contents is named as C-AEM-n-m wt $\%$ (m $\mathrm{wt} \%$ means the weight percentage of graphene in the PDDA solution).

\subsection{Characterization methods}

\subsubsection{ATR-FTIR spectra and SEM images}

Attenuated Total Reflection Fourier Transform Infrared Spectroscopy (ATR-FTIR) analyses were performed with a Thermo Nicolet FTIR spectrometer with the spectral range of $4000-500 \mathrm{~cm}^{-1}$ to confirm the presence of assembled multilayers. Furthermore, the SEM images of top view and cross-section of the prepared membranes were obtained with a field emission-scanning electron microscope (S-4800, Hitachi, Japan). Transmission electron microscopy (TEM) images were performed on an H-7650 microscope under an accelerate voltage of $100 \mathrm{kV}$.

\subsubsection{Water content and membrane resistance with layers}

Prior to analysis, all the membrane samples were soaked in deionized water at room temperature $\left(25^{\circ} \mathrm{C}\right)$ for $24 \mathrm{~h}$. The membranes were weighed immediately after using tissue paper to wipe off the water on membrane surface. The wet weight of the membrane was recorded as $\mathrm{W}_{\text {wet }}$. Afterwards, the membrane was dried in vacuum at $55^{\circ} \mathrm{C}$ for $24 \mathrm{~h}$ before weight. The dry weight was denoted as $\mathrm{W}_{\mathrm{dry}}$. The water content $\left(\mathrm{W}_{\mathrm{c}}\right)$ was calculated by [31]:

$\mathrm{W}_{\mathrm{c}}=\frac{\mathrm{W}_{\text {wet }}-\mathrm{W}_{\mathrm{dry}}}{\mathrm{W}_{\mathrm{dry}}} \times 100 \%$

where, $\mathrm{W}_{\text {wet }}$ and $\mathrm{W}_{\mathrm{dry}}$ are the mass of wet and dried membranes, respectively.

The resistance of these membranes was measured by a four-chamber electrodialysis cell (CJ-AMD-01, Chemjoy Polymer Materials Co., Ltd., Hefei, China). The measurement cell consists of two titanium coated ruthenium plate electrodes with a contacting area of $78.5 \mathrm{~cm}^{2}$. The solutions in electrode and another two chambers were $0.5 \mathrm{M} \mathrm{Na}_{2} \mathrm{SO}_{4}$ and $0.5 \mathrm{M} \mathrm{NaCl}$, respectively. Prior to the measurement, the membrane samples were soaked with $0.5 \mathrm{M} \mathrm{NaCl}$ for $0.5 \mathrm{~h}$. Afterwards, the membranes were cut into circular pieces of $4 \mathrm{~cm}$ in diameter and then were placed between two $\mathrm{Ag}-\mathrm{AgCl}$ reference electrodes on both sides (effective area $S=7.065 \mathrm{~cm}^{2}$ ). A constant current of 0.04 A (I) was supplied by a DC power source (MCH-k305D, Shenzhen, China), and the voltage $(\mathrm{U})$ between two electrodes was read through digital multimeters (model: UT39C, Uni-Trend Technology Limited, Guangzhou,
China). Prior to the measurements, a blank voltage $\left(\mathrm{U}_{\mathrm{o}}\right)$ was tested between two electrodes without membrane. The membrane area resistance $\left(R_{m}\right)$ was calculated by:

$\mathrm{R}_{\mathrm{m}}=\frac{\mathrm{U}-\mathrm{U}_{0}}{\mathrm{I}} \times \mathrm{S}$

where $\mathrm{U}$ and $\mathrm{U}_{\mathrm{o}}$ is the cell voltage with and without the membrane, respectively. $I$ is the current $0.04 \mathrm{~A}, \mathrm{~S}$ is the effective area $7.065 \mathrm{~cm}^{2}$.

\subsubsection{ED performance on ion selectivity and water migration control}

The ED setup was provided by Chemjoy (GJ-ED-100 $\times 200$, Chemjoy Polymer Materials Co., Ltd., Hefei, China). The ED stacks (ED 64004, PCCell GmbH) and cation exchange membranes (CEM: PC-SK) were purchased from PCCell GmbH (Heusweiler, Germany). The ED stack consisted of two piece of PC-SK and one piece of prepared AEM with silicone gaskets $(\sim 0.45 \mathrm{~mm})$ and woven PET fabric spacers in between. The effective membrane area was $64 \mathrm{~cm}^{2}(8 \mathrm{~cm} \times 8 \mathrm{~cm})$ for each. The electrical field was supplied by a DC power source (MCHk305D, Shenzhen, China), and the applied current was kept constant at $0.1 \mathrm{~A}$ (current density $15.625 \mathrm{~A} / \mathrm{m}^{2}$ ) during the ED experiments. The flow rate was kept at $10 \mathrm{~L} / \mathrm{h}$ for all the streams.

To investigate the anion selectivity of the modified membranes, $\mathrm{Na}_{2} \mathrm{SO}_{4}$ and $\mathrm{NaCl}$ were used as monovalent and divalent salts, respectively. As shown in Fig. 2, the modified AEM sample was fixed between two cation exchange membranes, and the modified surface faced to the diluate compartment (D chamber), which contained $0.01 \mathrm{M} \mathrm{Na}_{2} \mathrm{SO}_{4}$ and $0.01 \mathrm{M} \mathrm{NaCl}$. Deionized water and $0.1 \mathrm{M} \mathrm{Na}_{2} \mathrm{SO}_{4}$ were used in the concentrate compartment ( $\mathrm{C}$ chamber) and electrolyte rinsing solution, respectively. Each solution was $500 \mathrm{ml}$.

To investigate the prepared C-AEMs separation efficiency on organic ions, the same solution consisted of $0.05 \mathrm{M}$ sodium formate and $0.05 \mathrm{M}$ sodium hexanoate was used as both the diluate and the concentrate. $0.1 \mathrm{M} \mathrm{NaOH}$ was added to adjust $\mathrm{pH}$ of formic acid and hexanoic acid to 7. The electrode rinsing solution and the operating conditions were the same as that in the anion selectivity experiments.

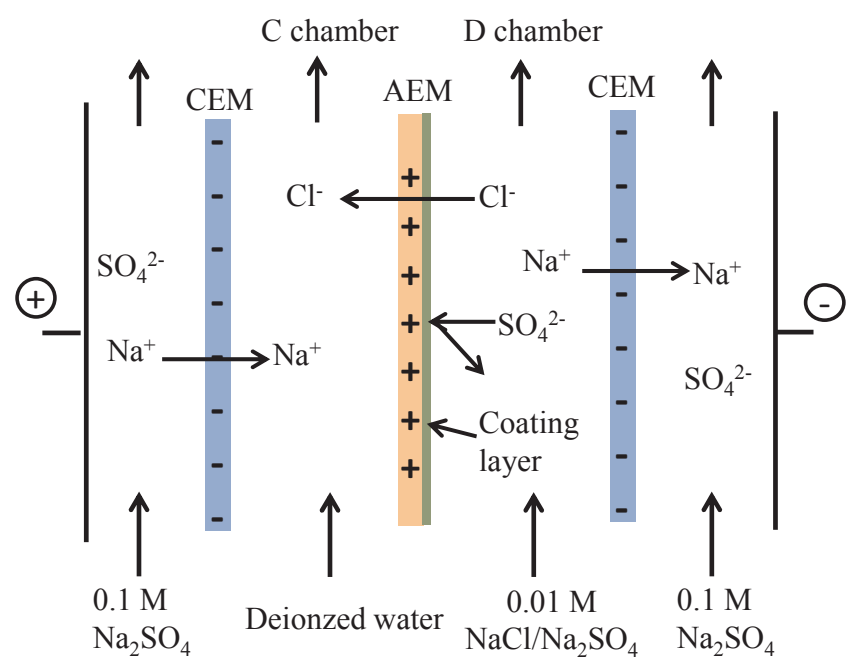

Fig. 2. Experimental setup of ED to evaluate the anion selectivity of the AEMs. 
Besides, the performance of C-AEMs on controlling water electroosmosis was studied by using $2 \mathrm{M} \mathrm{NaCl}$ solution. Each chamber was filled with $300 \mathrm{ml}$ solution, with the applied current density of $312.5 \mathrm{~A} /$ $\mathrm{m}^{2}$.

\subsubsection{Electrochemical characterization}

A four-chamber stack was employed for membrane electrochemical characterization. Two carbon wire electrodes were placed on both sides of the membrane, with amplitude of $10 \mathrm{mV}$ and frequency range was $10^{5}-10^{-1} \mathrm{~Hz}$ by an electrochemical workstation (model: CHI660E, $\mathrm{CH}$ instrument Co., Ltd., Shanghai, China) for Electrical Impedance Spectroscopy (EIS) measurement. Chronopotentiometry curves of the membranes were also determined by using the same apparatus. The applied current density was $15.625 \mathrm{~A} / \mathrm{m}^{2}$, voltage change was recorded over time. The test electrolyte solutions used in EIS and chronopotentiometry were $0.01 \mathrm{M} \mathrm{NaCl}$ and a $0.01 \mathrm{M} \mathrm{NaCl}+\mathrm{Na}_{2} \mathrm{SO}_{4}$, respectively.

\subsubsection{Evaluation of membrane selectivity}

To evaluate monovalent anion selectivity of the C-AEMs, ion flux through the membranes was obtained from the change in concentration of $\mathrm{M}^{\mathrm{n}-}$ ion on the $\mathrm{C}$ chamber $[32,33]$.

$\mathrm{J}_{\mathrm{M}^{\mathrm{n}}}=\frac{\left(\mathrm{C}_{\mathrm{t}}-\mathrm{C}_{0}\right) \cdot \mathrm{V}}{\mathrm{A}_{\mathrm{m}} \cdot \mathrm{t}}$

where $J_{M^{n-}}$ is the ion flux of $\mathrm{M}^{\mathrm{n}-}$ ion through the membrane $\left(\mathrm{mol} \mathrm{cm}{ }^{-2} \mathrm{~s}^{-1}\right) ; \mathrm{C}_{\mathrm{t}}$ and $\mathrm{C}_{0}(\mathrm{~mol} / \mathrm{L})$ are the concentration of the $\mathrm{M}^{\mathrm{n}-}$ ion at the $\mathrm{C}$ chamber at the time $\mathrm{t}$ and 0 , respectively; $\mathrm{V}$ is the volume $0.5 \mathrm{~L} ; \mathrm{A}_{\mathrm{m}}$ is the effective area of the membrane, which was $64 \mathrm{~cm}^{2}$.

The permselectivity between $\mathrm{SO}_{4}{ }^{2-}$ and $\mathrm{Cl}^{-}$ions $\left(P_{\mathrm{SO} 4}^{\mathrm{Cl}}\right)$ is defined by Eq. (4) [34].

$\mathrm{P}_{\mathrm{SO} 4}^{\mathrm{Cl}}=\frac{\mathrm{J}_{\mathrm{Cl}^{-}} \cdot \mathrm{C}_{\mathrm{SO}^{2-}}}{\mathrm{J}_{\mathrm{SO} 4^{2-}} \cdot \mathrm{C}_{\mathrm{Cl}^{-}}}$

where $J_{\mathrm{SO}_{4}^{2-}}$ and $\mathrm{J}_{\mathrm{Cl}^{-}}$denote the flux of $\mathrm{SO}_{4}{ }^{2-}$ and $\mathrm{Cl}^{-}$ions, respectively; $\mathrm{C}_{\mathrm{SO}_{4} 4^{2-}}$ and $\mathrm{C}_{\mathrm{Cl}^{-}}$are the ion concentrations in $\mathrm{D}$ chamber.

The separation performance of the organic anions (formate and hexanoate) is represented by migration percentage (MP). This factor is calculated by Eq. (5).

$\mathrm{MP}=\frac{\mathrm{C}_{\mathrm{if}}-\mathrm{C}_{\mathrm{i} 0}}{\mathrm{C}_{0}}$

where $\mathrm{C}_{\mathrm{if}}$ and $\mathrm{C}_{\mathrm{i} 0}$ are the final and initial concentration of $\mathrm{i}$ ion in $\mathrm{C}$ chamber.

\section{Result and discussion}

\subsection{Confirmation of the composite anion exchange membranes made by LbL method}

In order to confirm that the PSS/PDDA layers were successfully assembled onto the membrane surface, ATR-FTIR was used to test the base membrane and C-AEM-5.5. As shown in Fig. 3, the peak between 3200 and $3600 \mathrm{~cm}^{-1}$ is the absorption peak of functional group $-\mathrm{NH}_{4}$ on the base membrane surface, while that at 1530 and $1600 \mathrm{~cm}^{-1}$ is the bending vibration absorption peak of N-H. After LbL assembly onto the membrane surface, the intensity of the peaks was reduced or disappeared, while some new peaks are observed. Among them, the peak appeared between 1085 and $1127 \mathrm{~cm}^{-1}$ is the absorption peak of $-\mathrm{SO}_{3}$ group, and the peak at $1217 \mathrm{~cm}^{-1}$ represents -CN group of PDDA. These peaks indicate that the base membrane surface was modified by PSS and PDDA successfully.

Furthermore, SEM and TEM images were taken to feature the prepared C-AEM surface and the graphene material. Fig. 4(a) and Fig. 4(b) exhibit the surface of the base membrane and the prepared C-AEM-5.5, respectively. These two figures infer that the membrane surface was

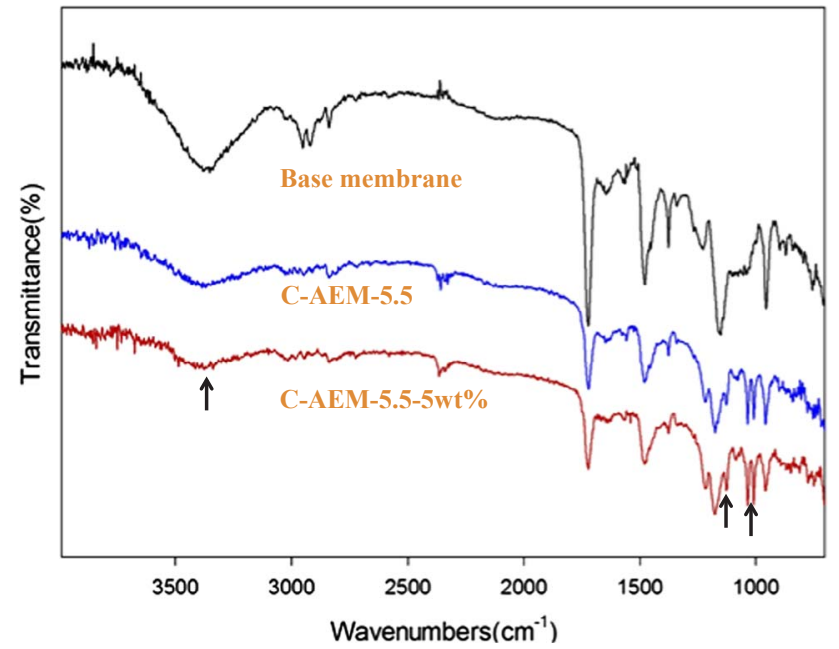

Fig. 3. ATR-FTIR spectra of base membrane and modified C-AEM-5.5 (C-AEM-5.5-5 wt $\%$ was the membrane doping $5 \mathrm{wt} \%$ graphene).

getting denser when PSS/PDDA layers were coated. Furthermore, the addition of graphene in PDDA resulted in a more rough membrane surface, as can be seen in Fig. 4(c) (C-AEM-5.5-5 wt\%). Fig. 4(d) is a confirmation by TEM image that the graphene material used in this study had a thin and layered structure. Moreover, the cross sections of base membrane and C-AEM-5.5 are shown in Fig. 5. It can be seen from Fig. 5(a) and (b) that the thickness of the base membrane is about $42.6 \mu \mathrm{m}$, while the thickness of LbL assembled 5.5 layers is about $900 \mathrm{~nm}$.

\subsection{Water content and membrane resistance with layers}

Correlations between membrane water content and the assembled layer numbers are shown in Fig. 6. As seen, water content of the base membrane is $19.23 \%$, and is increased with the layer numbers. When 10.5 layers are coated, the rate is increased to $27.61 \%$. This attributes to the fact that both PSS and PDDA are hydrophilic polymer materials. In addition, since graphene is a hydrophobic material, the membrane hydrophilicity is declined slightly after doping of graphene, as the water content of $5.5-0,5.5-5$ and $5.5-10$ is $26 \%, 23 \%$ and $20 \%$, respectively.

Literatures have reported that the coated multilayers would increase the membrane resistance, which resulted in a decrease of the current efficiency [32]. Table 2 listed the resistance of the modified membranes with different layers as well as that of ACS. Among them, the base membrane resistance was $1.813 \Omega \cdot \mathrm{cm}^{2}$, and ACS was $5.563 \Omega \cdot \mathrm{cm}^{2}$. With the increase of coated layers, the resistance of C-AEM membranes increased gradually, and reached $2.312 \Omega \cdot \mathrm{cm}^{2}$ when 10.5 layers was coated. However, the resistance of all the membranes was lower than that of ACS. This is due to the fact that the base membrane was much thinner than ACS and had no non-woven fabric as the support. Meanwhile, the resistance of the membranes doped with graphene was slightly lower than that of the corresponding membranes without graphene. This attributes to the reason that graphene is a highly conductive material with large surface area, which may provide channels for ion migration. Although the resistance of the LbL modified membranes was higher than that of the base membrane, it can be reduced by doping graphene into the layers. In fact, it was proved that doping of other carbon based materials (e.g., carbon nanotube, experimental results are not shown in this work) can also improve the conductance.

\subsection{Monovalent anion selectivity and organic ion separation with layers}

As shown in Fig. 7, the base membrane did not present monovalent 

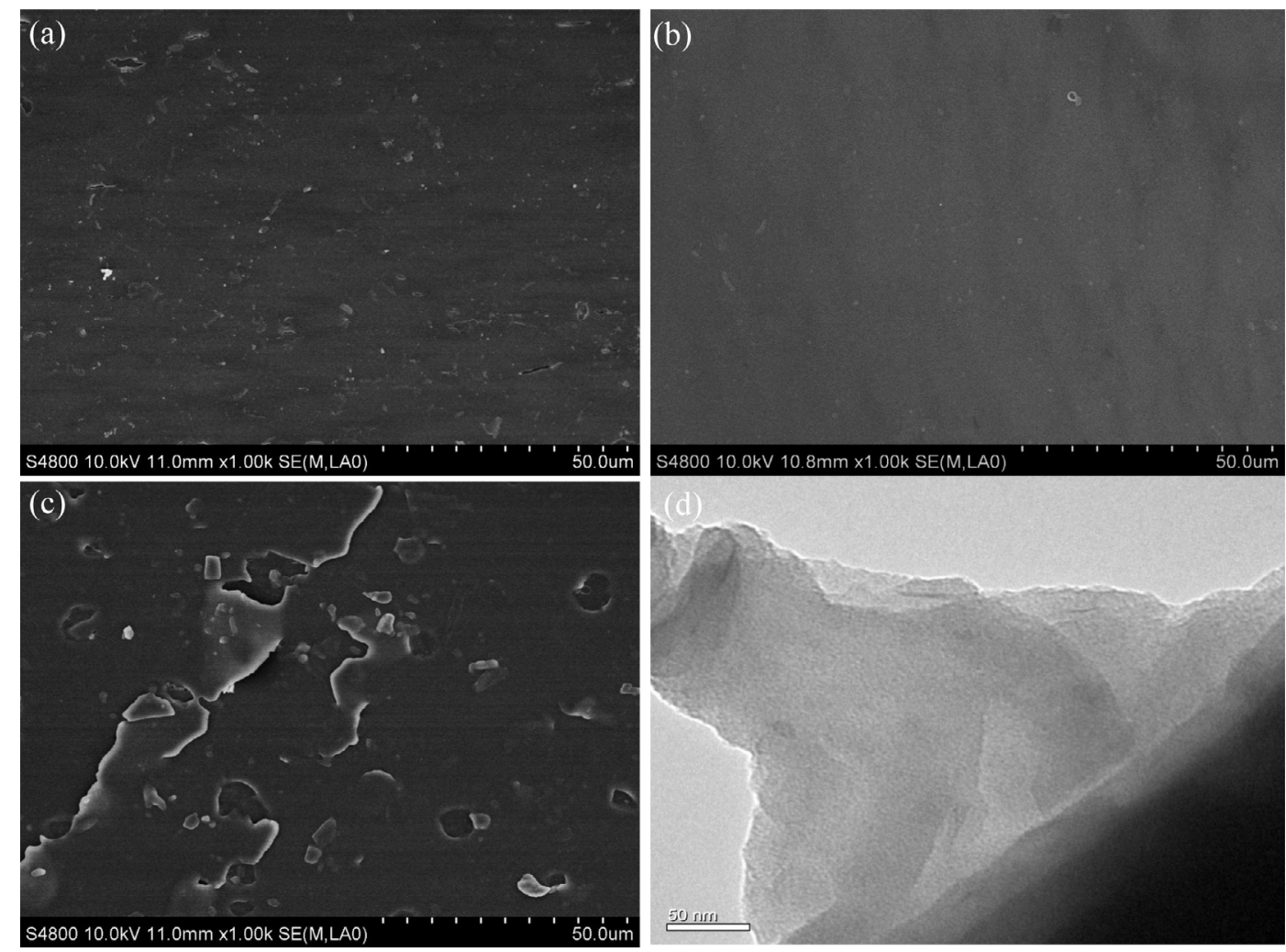

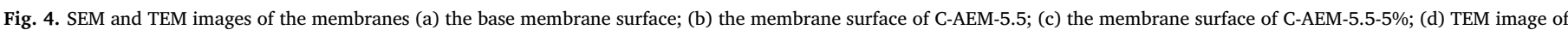
the graphene used in this work.

anion selectivity $\left(P_{S O 4}^{C l}\right)$ in the test condition, since the value is 1.0. While ACS showed a good selectivity with the $P_{S O 4}^{C l}=4.5$. For the LbL modified membranes, the selectivity between $\mathrm{Cl}^{-}$and $\mathrm{SO}_{4}{ }^{2-}$ gradually increased with the layers, especially when 10.5 layers were assembled, the membrane exhibited excellent selectivity, with $P_{\mathrm{SO} 4}^{C l}=11.5$. Table 3 lists the fabrication and the separation performances of various monovalent ion selective membranes. According to the Table 3, it can be seen that the permselectivity of $11.5\left(P_{\mathrm{SO} 4}^{C l}\right)$ in this study is one of the highest in view of the recent reported monovalent selective membranes. High permselectivity between chloride towards sulfate attributes to the fact that PSS provides negatively charged membrane surface, which repulses bivalent anion (sulfate) and hinders its passage. When more PSS layers are assembled onto the membrane surface, sulfate is repulsed by these negatively charged multilayers, this magnifies the charge repulsion effect [35]. Besides, the dense multilayers on the membrane surface also provide a steric hindrance effect, which hinders larger ions (sulfate) pass through the membrane. However, the diameter of the

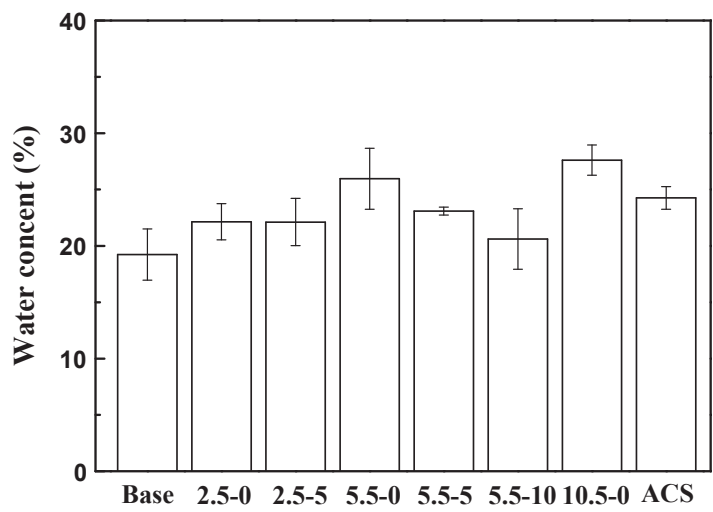

Fig. 6. The water content with assembled layers of C-AEM, in comparison with the base membrane and ACS.
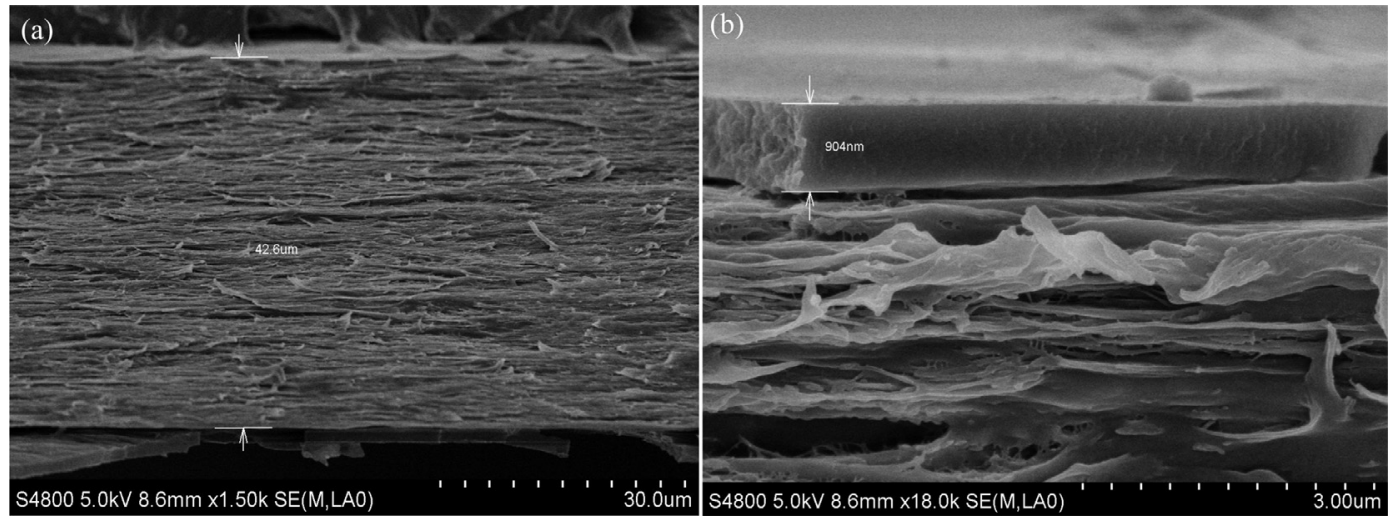

Fig. 5. SEM of the cross-sections of C-AEM-5.5 (a) the cross-section thickness of C-AEM-5.5 membrane; (b) the coated 5.5 layers. 
Table 2

The area resistance with assembled layers of C-AEM, in comparison with the base membrane and ACS.

\begin{tabular}{|c|c|c|c|c|c|c|c|}
\hline Type & Base & $\begin{array}{l}\text { C- } \\
\text { AEM- } \\
2.5\end{array}$ & $\begin{array}{l}\text { C-AEM- } \\
2.5-5 \mathrm{wt}\end{array}$ & $\begin{array}{l}\text { C- } \\
\text { AEM- } \\
5.5\end{array}$ & $\begin{array}{l}\text { C-AEM- } \\
5.5- \\
10 \mathrm{wt}\end{array}$ & $\begin{array}{l}\text { C- } \\
\text { AEM- } \\
10.5\end{array}$ & ACS \\
\hline Value $\left(\Omega \cdot \mathrm{cm}^{2}\right)$ & 1.813 & 1.974 & 1.956 & 2.148 & 2.029 & 2.312 & 5.563 \\
\hline
\end{tabular}

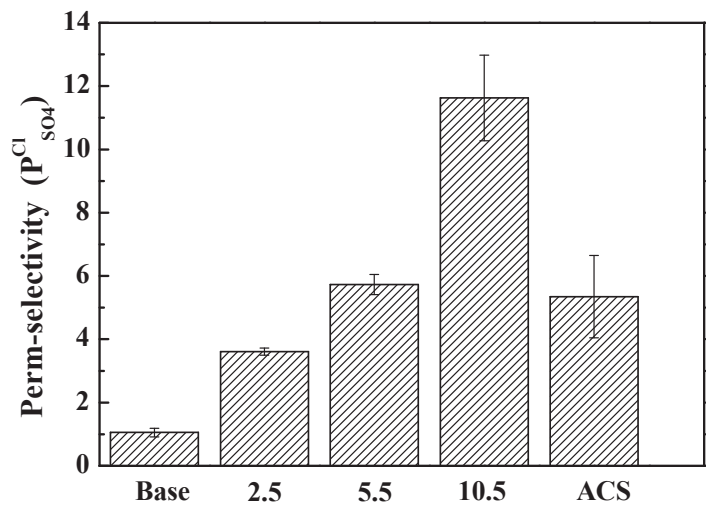

Fig. 7. The ions selectivity with assembled layers of C-AEM, in comparison with the base membrane and ACS.

Table 3

An overview of monovalent selective ion exchange membrane permselectivity in recent literatures.

\begin{tabular}{|c|c|c|c|}
\hline Method & Test condition & Permselectivity & Reference \\
\hline LbL of PSS/PDDA & $\begin{array}{l}0.01 \mathrm{M} \\
\mathrm{Na}_{2} \mathrm{SO}_{4}+0.01 \mathrm{M} \\
\mathrm{NaCl}\end{array}$ & $P_{\mathrm{SO} 4}^{C l}=11.5$ & This work \\
\hline $\begin{array}{l}\text { LbL of PSS/PAH PAH: poly } \\
\text { (allylaminehy- } \\
\text { drochloride) }\end{array}$ & $\begin{array}{l}0.01 \mathrm{M} \mathrm{NaCl} \\
+0.01 \mathrm{M} \mathrm{Na}_{2} \mathrm{SO}_{4}\end{array}$ & $\begin{array}{l}P_{C l}^{S O 4}=0.55 \\
\left(P_{S O 4}^{C l}=1.82\right)\end{array}$ & [19] \\
\hline $\begin{array}{l}\text { LbL of PSS/PEI PEI: poly } \\
\text { (ethyleneimine) }\end{array}$ & $\begin{array}{l}0.05 \mathrm{M} \mathrm{NaCl} \\
+0.05 \mathrm{M} \mathrm{CaCl}_{2}\end{array}$ & $P_{C a}^{N a}=1.35$ & [32] \\
\hline $\begin{array}{l}\text { Interfacial polymerization of } \\
\quad \text { a skin layer }\end{array}$ & $\begin{array}{l}0.459 \mathrm{M} \mathrm{NaCl} \\
+0.052 \mathrm{M} \mathrm{MgCl}_{2}\end{array}$ & $P_{M g}^{N a}=7$ & [36] \\
\hline $\begin{array}{l}\text { LbL of PDDA/NSBC/PDDA } \\
\text { NSBC: N-O-sulfonic acid } \\
\text { benzyl chitosan }\end{array}$ & $\begin{array}{l}0.02 \mathrm{M} \\
\mathrm{Na}_{2} \mathrm{SO}_{4}+0.02 \mathrm{M} \\
\mathrm{NaCl}\end{array}$ & $P_{S O 4}^{C l}=2.2$ & [37] \\
\hline $\begin{array}{l}\text { Electro-deposition of PSS/ } \\
\text { HACC HACC: } \\
\text { Hydroxypropyltrimethyl } \\
\text { ammonium chloride } \\
\text { chitosan }\end{array}$ & $\begin{array}{l}0.02 \mathrm{M} \\
\mathrm{Na}_{2} \mathrm{SO}_{4}+0.02 \mathrm{M} \\
\mathrm{NaCl}\end{array}$ & $P_{\mathrm{SO} 4}^{C l}=2.9$ & [38] \\
\hline
\end{tabular}

pore formed by the chain gap of PSS and PDDA has a limit. Therefore, the selectivity between $\mathrm{Cl}^{-}$and $\mathrm{SO}_{4}{ }^{2-}$ first increases with the layers then remains constant $[19,32]$.

Fig. 8 shows the comparison of conductivity between modified membranes with assembled layers and base membrane. The conductivity decline is in the order of Base membrane $>2.5-5 \mathrm{wt}$ $\%>5.5-5 \%>5.5-0 \%$. This attributes to the fact that a membrane with smaller resistance owns a higher ion transport rate. With the increase of assembled layer, the membrane resistance increases. When graphene was doped into the membrane, the membrane resistance decreased accordingly.

To further investigate steric hindrance effect of the LbL assembled membrane, organic ion selectivity experiments were performed. Fig. 9 shows the percentage of transferred formic acid and hexanoic acid through the C-AEM into the C chamber, as well as the selectivity towards these two organic ions. It can be seen from Fig. 9 that the migrated formate and hexanoate percentage was obviously different,

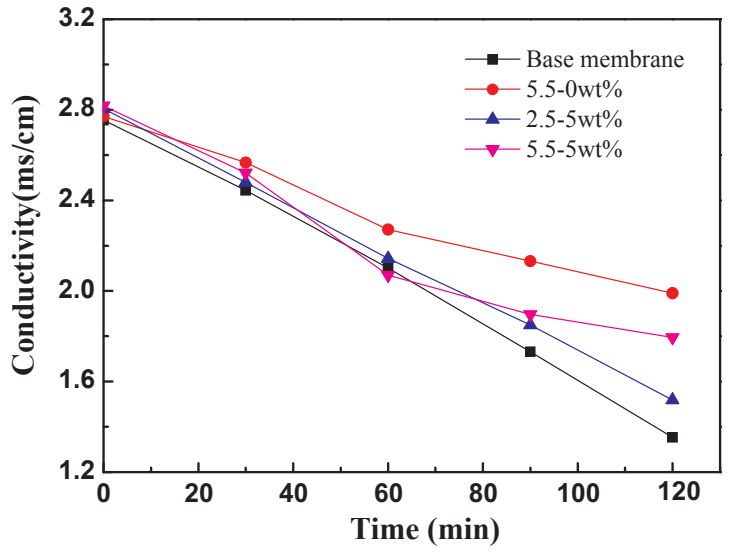

Fig. 8. Comparison of conductivity decline as a function of time between the layered membranes (with graphene content) and the base membrane.

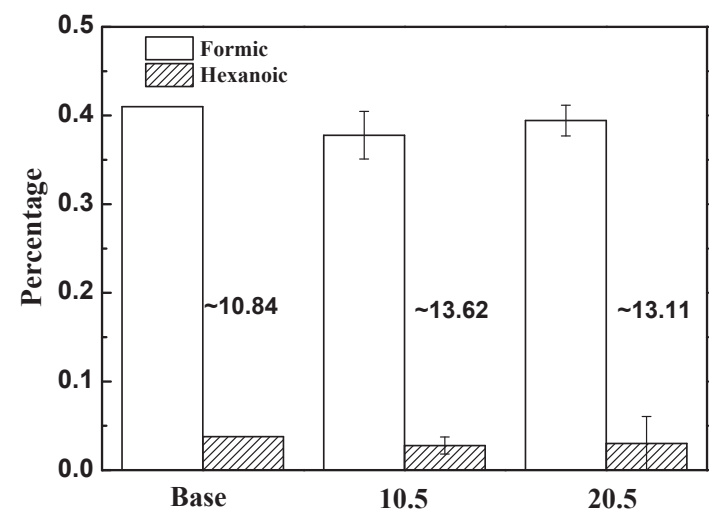

Fig. 9. The separation performance for formic acid and hexanoic acid for different layers C-AEM.

which is due to the molecular size and weight difference of these two ions. More specifically, $41.0 \%$ of formate $3.78 \%$ of hexanoate passed through the base membrane. The migrated formate was 10.84 times higher than that of hexanoate. The migration ratio of formate to hexanoate in 10.5 and 20.5 layers membranes was 13.62 and 13.11 , respectively. This infers that the membrane selectivity between organic ions was improved when more layers were coated, but the separation efficiency of a membrane with 20.5 coating layers was not better than that of with 10.5 layers. This may attribute to the fact that transport of organic ions is affected by both steric hindrance and adsorption. More layers on the top of a membrane indeed hinders the transport of organic ion through "cavity", but due to the nature of the material (PSS and PDDA in this work), organic ions still penetrate through the membrane via adsorption-diffusion mechanism. Therefore, the method by increasing top layers only has limited effect on improving organic ion selectivity. It should also be addressed that the percentage of transferred formate and hexanoate was reduced for both formate and hexanoate, when C-AEMs were used. The main reason of this phenomenon was the steric hindrance effect: the organic ions were getting more difficult to penetrate the coated membranes. As the modified layers gradually increased, the membrane surface became denser with smaller pore size than the base membrane.

\subsection{Control of water electro-osmosis with assembled layers}

The water migration volume by electro-osmosis with different membranes was tested in $2 \mathrm{M} \mathrm{NaCl}$ solution. From Fig. 10 it can be seen that the water co-transport rate was $52.5 \mathrm{ml} \cdot \mathrm{mol}^{-1} \cdot \mathrm{h}^{-1}$ when a base membrane was used. While C-AEM-10.5 showed $40 \mathrm{ml} \cdot \mathrm{mol}^{-1} \cdot \mathrm{h}^{-1}$ and 


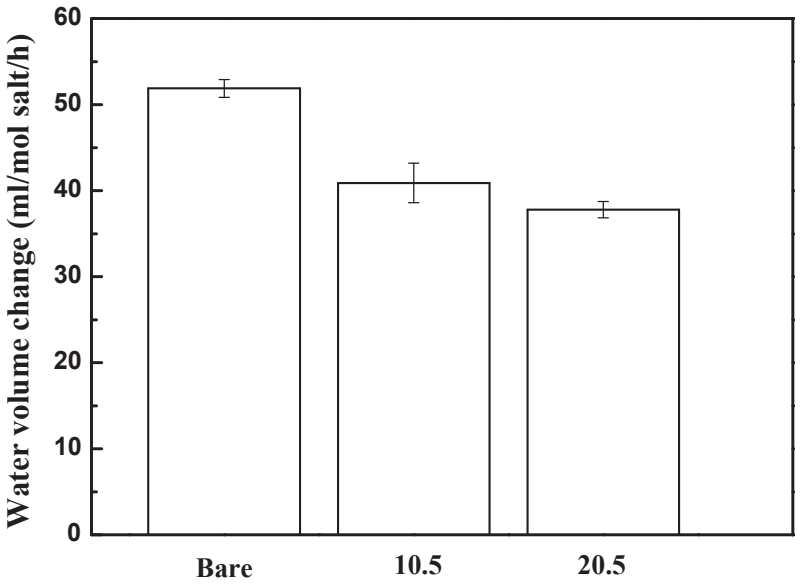

Fig. 10. The water migration volume through different membranes.

C-AEM-20.5 showed $37 \mathrm{ml} \cdot \mathrm{mol}^{-1} \cdot \mathrm{h}^{-1}$ of water transport (c.a. $30 \%$ reduction of water migration than the base membrane). This implies that the assembled layers can effectively hinder the water transport through anion exchange membrane. The explanation of this phenomenon is that the assembled dense layers can reduce the water molecule numbers at the outer shell of the hydrated anions.

\subsection{Electrochemical characterization}

EIS has been widely used in the characterization of IEMs as the advantages of providing detailed information about interface [39]. Fitting of EIS data using equivalent circuit is also helpful in understanding of ion transport mechanism. Typical equivalent circuit for IEMs was consisted with three parts as shown in inset plot of Fig. 11(a). The resistor $R_{s+m}$ at high frequency represented the total resistance of solution and membrane. The second part of equivalent circuit corresponding to medium frequency was theoretically consists of parallel connected resistor and capacitor (R-C elements), indicating the interface heterogeneous impedance of ion transport at electrical double layer. However, the fitting results usually deviated from theory, generating constant phase element (CPE) instead of capacitor. Reflecting in Nyquist plot, the semicircle deformed to a squashed semicircle with relative shorter diameter at imaginary impedance axis. The reason was considered to be the inhomogeneity of interface, i.e. disordered and rough membrane surface. Thus the actual resistance of ion transport at electrical double layer was fitting as parallel connected $R_{\text {edl }}$ and $\mathrm{CPE}_{\text {edl }}$. The last part of equivalent circuit expressed the ion migration at diffusion layer, corresponding to low frequency area. It is noticed that the typical circuit of this part is also parallel connected resistor and capacitor $[39,40]$. However, the fitting results in this work showed Warburg impedance, the possible reason was the large bulk solution volume in the electrodialysis cell $[39,41]$.

Then the EIS was performed to distinguish membrane properties in mixture of mono- and bivalent solutions. Compared with base membrane, Nyquist plot for 10.5 and 20.5 layers membrane in Fig. 11(b) showed obvious difference at interfacial heterogeneous transport area, similar with ACS membrane. For base membrane, the diameter of semicircle was larger, indicating that the ion transport impedance at interface was bigger than others. The possible interpretation was for base membrane, both mono- and bivalent ions transport through membrane, caused bigger heterogeneous transport impedance. While for 10.5, 20.5 layers and ACS membrane, only monovalent ions migrated through membrane, producing relative smaller heterogeneous transport impedance.

Chronopotentiometry is an electrochemical method used to measure the change of voltage response with time under a constant current. Compared with steady test, such as EIS, chronopotentiometry curve
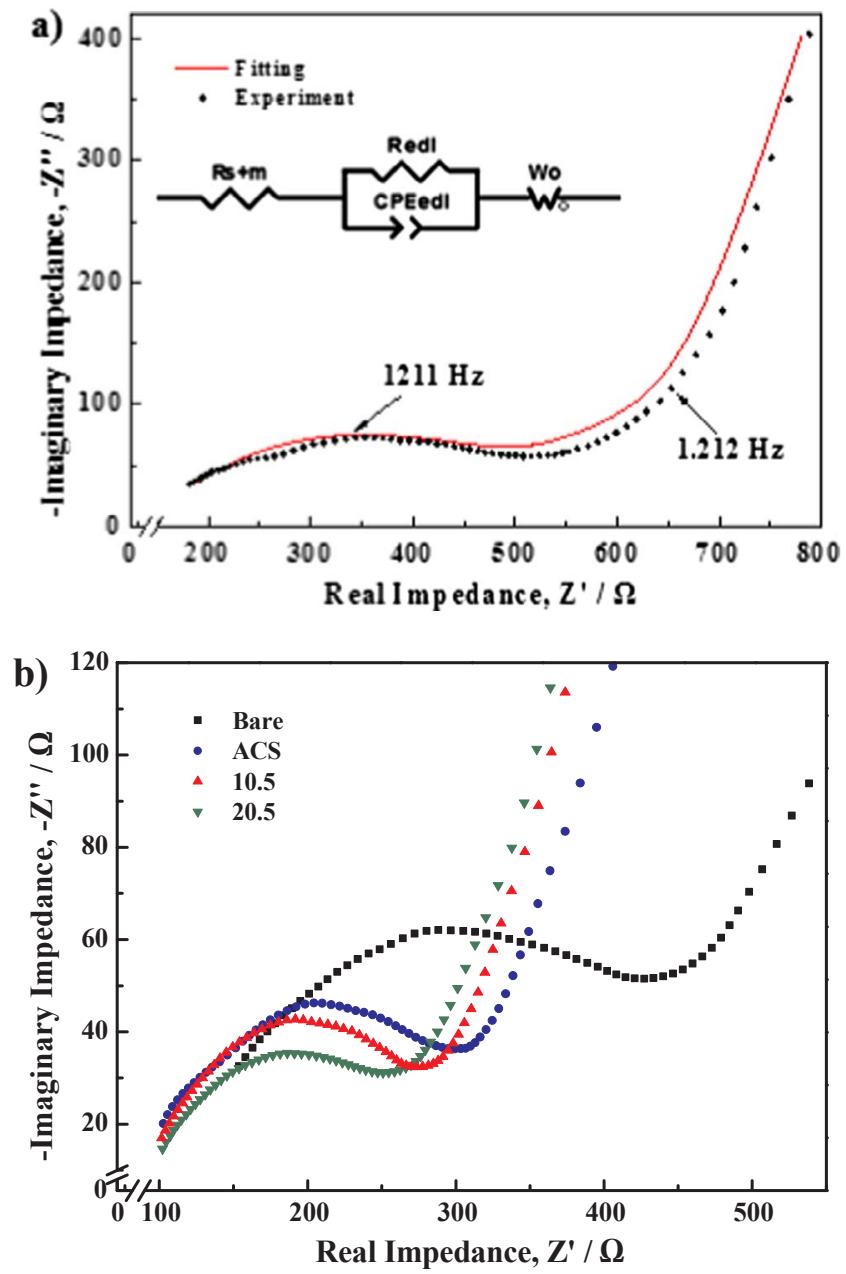

Fig. 11. (a) The Nyquist plot and fitting curve for 10.5 layers membrane in $0.01 \mathrm{M} \mathrm{NaCl}$ solution. Inset: equivalent circuit; (b) the Nyquist plot for base, ACS, coating 10.5 and 20.5 layers membranes in a $0.01 \mathrm{M} \mathrm{NaCl}$ and $\mathrm{Na}_{2} \mathrm{SO}_{4}$ mixture solution.

provide more details in dynamic behavior. For this reason, chronopotentiometry is applied in the investigation of charge transport process through membrane $[42,43]$. Furthermore, voltage change in different period and the corresponding time could characterize the behavior of ions around the diffusion boundary layer [44,45]. Thus chronopotentiometry was performed in this work to support the understanding of dynamic properties of mono- and bivalent ions through various membranes.

As shown in Fig. 12(a), chronopotentiometry curves for membranes in $0.01 \mathrm{M} \mathrm{NaCl}$ were obtained with clearly different sections. First section was mainly corresponding to ohmic potential drop caused by the imposed current. Then the slope of curve decreased, indicating the formation of ion depleting layer at membrane-solution interface. After that, the voltage increased sharply, representing another transport process, possibly contributed from water splitting and convection. And the time at the inflection point is named transition time $\tau$. Finally the voltage reached to a steady period and the curve became level again and remained. In monovalent solution, i.e., $0.01 \mathrm{M} \mathrm{NaCl}$, no obvious differences showed in chronopotentiometry curves for four kinds of membranes. Similar values of $\tau$ were obtained for different membranes (Fig. 12(a), cross points of dotted line with time axis).

While in the measurement of mono- and bivalent mix solution, transition time for different membranes drifted from each other, increased from base membrane, ACS, 10.5 to 20.5 layers membrane (Fig. 12(b)). In the mixed solution, the electrochemical properties and transport properties of membrane mainly depends on the membrane 

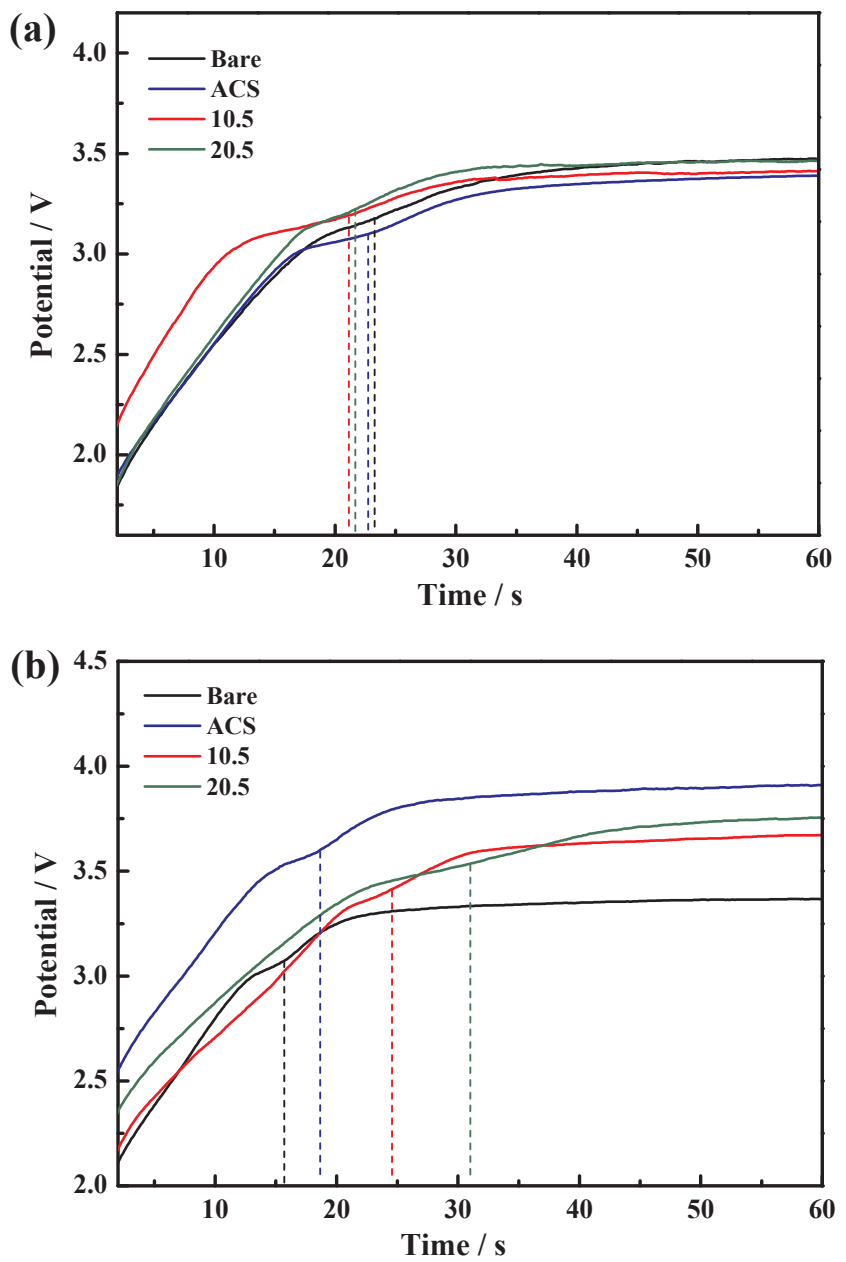

Fig. 12. The chronopotentiometry curves of different membranes measured in (a) $0.01 \mathrm{M}$ $\mathrm{NaCl}$ solution; (b) mixture solution of $0.01 \mathrm{M} \mathrm{NaCl}$ and $\mathrm{Na}_{2} \mathrm{SO}_{4}$.

surface functional groups and the interaction between the ion species, and the membranes with different aperture size have different sieve effect on ions [46]. That is, both mono- and bivalent ions migrated across the base membrane, thus the ions depleted quickly for base membrane, leading to the smallest value of $\tau$. However for ACS, monovalent ions transported through membrane, meanwhile most bivalent ions was blocked and accumulated at membrane surface under the application of current. With the accumulation of charge, bivalent ions diffused back to bulk solution against the electric field, following the depleted layer formation. Thus the generating of depleted layer was delayed, leading to the increase of transition time $\tau$. With the addition of coating layers, more bivalent ions were blocked by membrane, thus the value of transition time $\tau$ became larger. Besides, the values of $\tau$ were all in the range of 15.5-31.2 s, consistent with the range between 10 and $40 \mathrm{~s}$ reported by literature [45].

\section{Conclusion}

A layer by layer (LbL) assembly method is developed to prepare composite anion exchange membrane with functionalities. Firstly, monovalent/bivalent anion selectivity was examined. It was concluded that the chloride/sulfate selectivity $\left(P_{\mathrm{SO} 4}^{\mathrm{Cl}}\right)$ increased as the increase of assembled layers. When 10.5 layers were assembled, $P_{S O 4}^{C l}$ reached 11.5, this value was much higher than that of the commercial monovalent anion selective membrane (ACS, $P_{S O 4}^{C l}=4.5$ ). On the other hand, as the increment of electrical resistance is one of the drawbacks of the LbL method used to prepare functional ion exchange membranes, graphene with different weight percentage was doped into PDDA layer to reduce electrical resistance of the prepared membranes. Results indicate that only a slight reduction of electrical resistance was obtained.

In addition, the modified anion exchange membranes were also evaluated by the performance of organic anion separation. It was found that the organic anion selectivity increased with the assembled layers, due to the fact that the surface was getting denser when more layers were assembled.

Furthermore, the modified membranes exhibited good performance to reduce water migration through the membrane. Results showed that the water migration volume can be reduced by c.a. $30 \%$ when a C-AEM20.5 membrane was applied. This can be explained by the steric hindrance effect: the assembled dense layers can reduce the water molecule numbers at the outer shell of the hydrated anions

Results prove that the LbL assembly method can successfully control the surface properties (surface charge and pore size) of the anion exchange membrane, and provide a good separation efficiency of mono/ bi-valent anions and organic anions. Meanwhile, the membranes can also reduce water migration to the concentrate, this is a promising result with regard to elevate the concentration of concentrate, hence the ED performance can be improved. It is believed that functional composite ion exchange membranes with enhanced separation efficiency and water retention can be used in water desalination, salt fractionation, resource recovery and other related fields.

\section{Acknowledgement}

The authors would like to appreciate the financial support of the National Science and Technology Major Project of the Ministry of Science and Technology (2016ZX05040-003), the National Natural Science Foundation of China (No. 51508548), the Applied Basic Research Programs for Young Scientists of Qingdao (16-5-1-33-jch) and the Shandong Provincial Natural Science Foundation, China (No. BS2014NJ019). Tianwei Membrane Technology Co. Ltd. is acknowledged for the donation of anion exchange membranes.

\section{References}

[1] H. Strathmann, Introduction to Membrane Science and Technology, Wiley-VCH, 2011.

[2] T. Sata, Studies on anion exchange membranes having permselectivity for specific anions in electrodialysis-effect of hydrophilicity of anion exchange membranes on permselectivity of anions, J. Membr. Sci. 167 (2000) 1-31.

[3] L. Firdaous, J.P. Maleriat, J.P. Schlumpf, F. Quemeneur, Transfer of monovalent and divalent cations in salt solutions by electrodialysis, Sep. Sci. Technol. 42 (2007) 931-948.

[4] B. Tansel, Significance of thermodynamic and physical characteristics on permeation of ions during membrane separation: hydrated radius, hydration free energy and viscous effects, Sep. Purif. Technol. 86 (2012) 119-126.

[5] J.-X. Zhuang, Q. Chen, S. Wang, W.-M. Zhang, W.-G. Song, L.-J. Wan, K.-S. Ma, C.N. Zhang, Zero discharge process for foil industry waste acid reclamation: coupling of diffusion dialysis and electrodialysis with bipolar membranes, J. Membr. Sci. 432 (2013) 90-96.

[6] L.L. Tavlarides, J.H. Bae, C.K. Lee, Solvent extraction, membranes, and ion exchange in hydrometallurgical dilute metals separation, Sep. Sci. Technol. 22 (1987) 581-617.

[7] B.-X. Cai, Study of membrane separation processes of a betaine-like medicinal solution, Desalination 191 (2006) 432-437.

[8] T. Kawahara, Construction and operation experience of a large-scale electrodialysis water desalination plant, Desalination 96 (1994) 341-348.

[9] C. Jiang, Y. Wang, Z. Zhang, T. Xu, Electrodialysis of concentrated brine from RO plant to produce coarse salt and freshwater, J. Membr. Sci. 450 (2014) 323-330.

[10] P.J. Moon, S.J. Parulekar, S.P. Tsai, Competitive anion transport in desalting of mixtures of organic acids by batch electrodialysis, J. Membr. Sci. 141 (1998) 75-89.

[11] A. Bailly, H. Roux-de Balmann, P. Aimar, F. Lutin, M. Cheryan, Production processes of fermented organic acids targeted around membrane operations: design of the concentration step by conventional electrodialysis, J. Membr. Sci. 191 (2001) $129-142$.

[12] M. Mulder, Basic Principles of Membrane Technology, second ed., Kluwer Academic Publishers, 1996.

[13] J.L. Stair, J.J. Harris, M.L. Bruening, Enhancement of the ion-transport selectivity of layered polyelectrolyte membranes through cross-linking and hybridization, Chem. Mater. 13 (2001) 2641-2648.

[14] T. Sata, T. Yamaguchi, K. Matsusaki, Interaction between anionic polyelectrolytes 
and anion exchange membranes and change in membrane properties, J. Membr. Sci. 100 (1995) 229-238.

[15] T. Sata, K. Kawamura, K. Matsusaki, Electrodialytic transport properties of anionexchange membranes prepared from poly (vinyl alcohol), poly (N-ethyl 4-vinylpyridinium salt) and $\beta$-cyclodextrin, J. Membr. Sci. 181 (2001) 167-178.

[16] T. Sata, T. Yamaguchi, K. Matsusaki, Effect of hydrophobicity of ion-exchange groups of anion-exchange membranes on permselectivity between 2 anions, J. Phys. Chem. 99 (1995) 12875-12882.

[17] T. Sata, K. Mine, M. Higa, Change in permselectivity between sulfate and chloride ions through anion exchange membrane with hydrophilicity of the membrane, J. Membr. Sci. 141 (1998) 137-144.

[18] F. Quéméneur, J.-P. Schlumpf, L. Firdaous, M. Stitou, J.-P. Malériat, P. Jaouen, Modification of ionic composition of natural salt-waters by electrodialysis, Desalination 149 (2002) 411-416.

[19] S. Mulyati, R. Takagi, A. Fujii, Y. Ohmukai, H. Matsuyama, Simultaneous improvement of the monovalent anion selectivity and antifouling properties of an anion exchange membrane in an electrodialysis process, using polyelectrolyte multilayer deposition, J. Membr. Sci. 431 (2013) 113-120.

[20] M. Vaselbehagh, H. Karkhanechi, R. Takagi, H. Matsuyama, Surface modification of an anion exchange membrane to improve the selectivity for monovalent anions in electrodialysis - experimental verification of theoretical predictions, J. Membr. Sci. 490 (2015) 301-310.

[21] K. Hoffmann, A. El-Hashani, B. Tieke, Ion-selective membranes prepared upon layer-by-layer assembly of azamacrocycles and polyelectrolytes, Macromol. Symposia 287 (2010) 22-31.

[22] J.B. Schlenoff, H. Ly, M. Li, Charge and mass balance in polyelectrolyte multilayers, J. Am. Chem. Soc. 120 (1998) 7626-7634.

[23] J.B. Schlenoff, S.T. Dubas, Mechanism of polyelectrolyte multilayer growth: charge overcompensation and distribution, Macromolecules 34 (2001) 592-598.

[24] J. Tanninen, M. Manttari, M. Nystrom, Effect of salt mixture concentration on fractionation with NF membranes, J. Membr. Sci. 283 (2006) 57-64.

[25] Y. Zhang, B. Van der Bruggen, L. Pinoy, B. Meesschaert, Separation of nutrient ions and organic compounds from salts in RO concentrates by standard and monovalent selective ion-exchange membranes used in electrodialysis, J. Membr. Sci. 332 (2009) 104-112.

[26] H. Takahashi, R. Sugawara, K. Kikuchi, Permeation behavior of formic acetic, propionic, and butyric acids in electrodialysis, Kagaku Kogaku Ronbunshu 39 (2013) 184-189.

[27] L. Han, S. Galier, H. Roux-de, Balmann ion hydration number and electro-osmosis during electrodialysis of mixed salt solution, Desalination 373 (2015) 38-46.

[28] S.U. Hong, R. Malaisamy, M.L. Bruening, Optimization of flux and selectivity in $\mathrm{Cl}^{-} / \mathrm{SO}_{4}{ }^{2-}$ separations with multilayer polyelectrolyte membranes, J. Membr. Sci. 283 (2006) 366-372.

[29] O. Lu, R. Malaisamy, M.L. Bruening, Multilayer polyelectrolyte films as nanofiltration membranes for separating monovalent and divalent cations, J. Membr. Sci. 310 (2008) 76-84.

[30] W. Shan, P. Bacchin, P. Aimar, M.L. Bruening, V.V. Tarabara, Polyelectrolyte multilayer films as backflushable nanofiltration membranes with tunable hydrophilicity and surface charge, J. Membr. Sci. 349 (2010) 268-278.

[31] T. Xu, W. Yang, Fundamental studies of a new series of anion exchange membranes: membrane preparation and characterization, J. Membr. Sci. 190 (2001) 159-166.

[32] S. Abdu, M.-C. Marti-Calatayud, J.E. Wong, M. Garcia-Gabaldon, M. Wessling, Layer-by-layer modification of cation exchange membranes controls ion selectivity and water splitting, ACS Appl. Mater. Interfaces 6 (2014) 1843-1854.

[33] T. Sata, T. Sata, W.K. Yang, Studies on cation-exchange membranes having permselectivity between cations in electrodialysis, J. Membr. Sci. 206 (2002) 31-60.

[34] T. Sata, K. Mine, Y. Tagami, M. Higa, K. Matsusaki, Changing permselectivity between halogen ions through anion exchange membranes in electrodialysis by controlling hydrophilicity of the membranes, J. Chem. Soc. Faraday Trans. 94 (1998) 147-153.

[35] L. Krasemann, B. Tieke, Selective ion transport across self-assembled alternating multilayers of cationic and anionic polyelectrolytes, Langmuir 16 (2000) 287-290.

[36] L. Ge, B. Wu, Q, Li, Y. Wang, D. Yu, L. Wu, J, Pan, J. Miao, T. Xu, Electrodialysis with nanofiltration membrane (EDNF) for high-efficiency cations fractionation, J. Membr. Sci. 498 (2016) 192-200.

[37] Y. Zhao, H. Liu, K. Tang, Y. Jin, J. Pan, B.V. der Bruggen, J. Shen, C. Gao, Mimicking the cell membrane: bio-inspired simultaneous functions with monovalent anion selectivity and antifouling properties of anion exchange membrane, Sci. Rep. 6 (2016) 37285.

[38] Y. Zhao, K. Tang, H. Liu, B. Van der Bruggen, A. Sotto Diaz, J. Shen, C. Gao, An anion exchange membrane modified by alternate electro-deposition layers with enhanced monovalent selectivity, J. Membr. Sci. 520 (2016) 262-271.

[39] J.-S. Park, J.-H. Choi, J.-J. Woo, S.-H. Moon, An electrical impedance spectroscopic (EIS) study on transport characteristics of ion-exchange membrane systems, J. Colloid Interface Sci. 300 (2006) 655-662.

[40] W. Zhang, J. Ma, P. Wang, Z. Wang, F. Shi, H. Liu, Investigations on the interfacial capacitance and the diffusion boundary layer thickness of ion exchange membrane using electrochemical impedance spectroscopy, J. Membr. Sci. 502 (2016) 37-47.

[41] S.A. Mareev, V.V. Nikonenko, A numerical experiment approach to modeling impedance: application to study a warburg-type spectrum in a membrane system with diffusion coefficients depending on concentration, Electrochim. Acta 81 (2012) 268-274.

[42] N. Pismenskaia, P. Sistat, P. Huguet, V. Nikonenko, G. Pourcelly, Chronopotentiometry applied to the study of ion transfer through anion exchange membranes, J. Membr. Sci. 228 (2004) 65-76.

[43] J.J. Krol, M. Wessling, H. Strathmann, Chronopotentiometry and overlimiting ion transport through monopolar ion exchange membranes, J. Membr. Sci. 162 (1999) 155-164.

[44] P. Sistat, G. Pourcelly, Chronopotentiometric response of an ion-exchange membrane in the underlimiting current-range. Transport phenomena within the diffusion layers, J. Membr. Sci. 123 (1997) 121-131.

[45] S.A. Mareev, D.Y. Butylskii, N.D. Pismenskaya, V.V. Nikonenko, Chronopotentiometry of ion-exchange membranes in the overlimiting current range. Transition time for a finite-length diffusion layer: modeling and experiment, J. Membr. Sci. 500 (2016) 171-179.

[46] C. Klaysom, S.-H. Moon, B.P. Ladewig, G.Q.M. Lu, L. Wang, Preparation of porous ion-exchange membranes (IEMs) and their characterizations, J. Membr. Sci. 371 (2011) 37-44. 